\title{
85 anos: mudanças contínuas no caminho da excelência
}

\section{5 years: continuous changes in the pathway to excellence}

Há 85 anos, os Anais Brasileiros de Dermatologia tornavam-se o periódico definitivamente oficial dos dermatologistas brasileiros. Para comemorarmos tal fato, confeccionamos um selo que estará impresso na capa durante o volume 85.

O longo percurso traçado nas suas páginas contém o que há de mais representativo na evolução dessa especialidade no País.

É com orgulho que este número é dedicado ao precursor no 1, Anno 1 dos ANNAES BRASILEIROS DE DERMATOLOGIA E SYPHILOGRAPHIA, publicado em janeiro de 1925.

Os artigos daquele primeiro número versaram sobre acantose nigricante, leishmaniose, bouba, pênfigo e cistos epidérmicos, sarcomatose múltipla hemorrágica de Kaposi, xeroderma pigmentoso, o bismuto na terapêutica da sífilis e a história da sífilis no Brasil. ${ }^{1}$

Mesmo com o avanço dos conhecimentos científicos e com a melhoria geral das condições da saúde pública (em comparação com 1925), ainda há muita preocupação das autoridades sanitárias brasileiras com ... a sífilis e a leishmaniose, entre outras dermatoses seculares e reermegentes! Mas, às antigas preocupações somam-se outras. E a Dermatologia brasileira deve ser capaz de fornecer respostas aos novos desafios e ir além "do aplicar bem os conhecimentos produzidos no exterior". Ela deve refletir, interagir, investigar, sugerir hipóteses e ser propositiva, sempre com correção ética e com o foco principal no paciente, no cidadão.

Nesse contexto, gostaria de destacar no presente número (no 1, v. 85) a revisão da literatura elaborada por Gozzoni ML e Pires SL, do Departamento de Clínica Médica da Faculdade de Ciências Médicas da Santa Casa de São Paulo. Sob o peso de uma análise de 110 artigos, os autores produziram o artigo "Há evidências científicas na medicina antienvelhecimento?". Com apenas um estudo randomizado e duplo-cego encontrado, os autores demonstram a falta de base científica para muitas condutas terapêuticas defendidas por determinados segmentos. Seria o envelhecer uma "doença" a ser medicada perma- nentemente? Seria a Dermatologia refém dessa percepção induzida por poderosos meios?

A qualidade dos atuais Anais Brasileiros de Dermatologia pode ser também representada pelos demais artigos deste número e exemplificada pelos trabalhos da seção Comunicação: a Malassezia furfur é o principal agente da pitiríase versicolor (Framil VMS e col., p. 111-4) É possível elaborar estratégias

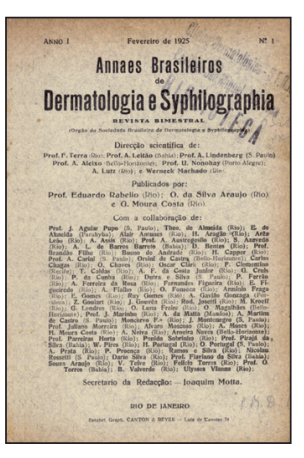
preventivas para diminuir os riscos de intercorrências nas cirurgias dermatológicas e seguir um fluxograma de conduta caso estas ocorram (Timoner FR e col., p. 115-8)

No âmbito da sempre necessária parceria Dermatologia-Clínica Médica, recomendaria uma atenta leitura do artigo de investigação sobre a possível associação entre a presença de acrocórdons e a resistência insulínica (Tamega AA e col., p. 25-32).

Representando as novas seções deste periódico, em Imagens em Dermatologia, o trabalho demonstrando os aspectos dermatoscópicos da psoríase ungueal pode ser de grande utilidade prática no cotidiano de todos (Farias AC e col., p. 101-4).

No suplemento do presente número, o artigo de Lupi O e colaboradores ("Doenças dermatológicas no Brasil: perfil atitudinal e epidemiológico") apresenta, de forma precursora, dados sobre um conjunto de fatores que realizam uma complexa interface entre uma amostra populacional brasileira e aspectos da Dermatologia praticada no país. Convido à leitura e à reflexão.

Finalizo este espaço de comunicação lembrando as novas seções abertas para os autores, Imagens em Dermatologia Tropical e Imagens em Dermatologia, bem como as novas normas vigentes para a publicação dos artigos (entre elas, a substituição de caracteres por palavras, na quantificação do espaço ocupado pelos trabalhos).

Feliz aniversário aos Anais Brasileiros de Dermatologia e parabéns a todos os dermatologistas que prestigiam nosso periódico!

\section{REFERÊNCIAS}

1. Annaes Brasileiros de Dermatologia e Syphilographia. 1925;1(1):1-82. 